\title{
Use of added sugars in packaged foods sold in Brazil
}

\author{
Tailane Scapin ${ }^{1}$, Ana Carolina Fernandes ${ }^{1,2}$, Adilson dos Anjos ${ }^{3}$ and Rossana Pacheco da \\ Costa Proença ${ }^{1,2, *}$ \\ 'Nutrition Postgraduate Program (Programa de Pós-graduação em Nutrição - PPGN) and Nutrition in Foodservice \\ Research Centre (Núcleo de Pesquisa de Nutrição em Produção de Refeições - NUPPRE), Federal University of Santa \\ Catarina (Universidade Federal de Santa Catarina - UFSC), Health Sciences Centre, Reitor João David Ferreira Lima \\ Campus, Florianópolis - SC, 88040-900, Brazil: ${ }^{2}$ Department of Nutrition (Departamento de Nutrição), Federal \\ University of Santa Catarina (Universidade Federal de Santa Catarina - UFSC), Health Sciences Centre, \\ Florianópolis, SC, Brazil: ${ }^{3}$ Department of Statistics (Departamento de Estatística), Federal University of Paraná \\ (Universidade Federal do Paraná - UFPR), Curitiba, PR, Brazil
}

Submitted 28 September 2017: Final revision received 27 June 2018: Accepted 31 July 2018: First published online 30 August 2018

\begin{abstract}
Objective: Studies have shown that the consumption of added sugars may be associated with harmful health effects. The present study investigated the presence and types of added sugars in packaged foods.

Design: Cross-sectional analysis of the presence and types of added sugars in the ingredients lists of packaged foods sold in a major Brazilian supermarket. The nomenclature of ingredients classified as added sugars and their frequency were identified. Data were organised and analysed through descriptive statistics: absolute and relative frequencies of the presence of added sugars categorised by food groups were calculated, and ingredients were analysed by text mining using R statistical environment.

Setting: A supermarket in Florianópolis, a metropolis in southern Brazil.

Subjects: Packaged food products ( $n$ 4539) classified into eight groups.

Results: Of the 4539 products, $71 \%$ had some type of added sugar. The group with the highest frequency of added sugars was 'products in which carbohydrates and fats are the main energy source' (93\%). Food groups containing predominantly salty foods had a high frequency of added sugars, such as 'meats and eggs' (61\%). In total, 179 different terms for added sugars were identified, of which sugar, maltodextrin and glucose syrup were the most frequent.

Conclusions: Most of the packaged foods sold in Brazil contain added sugars, which may hamper adherence to the recommendation of limiting added sugars intake. The data may be useful for monitoring tendencies in the use of added sugars in packaged foods and as supplementary information to support the improvement of food label regulations.
\end{abstract}

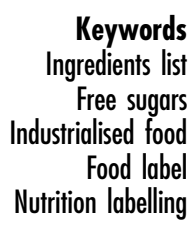

Added sugars are sugars and syrups that are added to foods or beverages during processing or preparation. These include ingredients such as refined sugar, highfructose corn syrup, honey and fruit juice concentrate, among others. The term 'added sugars' does not include naturally occurring sugars in foods, such as lactose in milk and sucrose and/or fructose in fruits and vegetables $^{(1-3)}$.

Systematic reviews and meta-analyses provide substantial evidence that a high intake of added sugars is associated with an increased risk of several diseases, specifically dental caries ${ }^{(4)}$, obesity ${ }^{(5)}$ and CVD $^{(6)}$. Consequently, the WHO recommends a low intake of added sugars throughout the life course as well as limiting consumption to less than 5-10\% of total daily energy intake ${ }^{(7)}$.

As packaged foods seem to be the main source of added sugars in many countries ${ }^{(8-13)}$, food labelling is a tool for consumers to make informed choices regarding the intake of added sugars ${ }^{(14)}$. Although some places such as Chile ${ }^{(15)}$, Australia and New Zealand ${ }^{(16)}$ and the European Union $^{(17)}$ require a declaration of total sugars on nutrition labels, only the $\mathrm{USA}^{(2)}$ and Canada ${ }^{(18)}$ require that the amount of added sugars be specified. On the other hand, in places where the quantitative declaration of sugars on food labels is not mandatory (e.g. Brazil), the identification of added sugars is possible only through the 
ingredients list. Thus, it can be presumed that individuals find it difficult to adhere to the WHO recommendation of limiting added sugars intake using food labels, because consumers in most countries can identify the presence of added sugars only through the ingredients list, without having access to detailed information on the amount of added sugars in packaged foods.

Few studies have investigated the presence of added sugars in packaged foods sold in supermarkets considering a large number of products from several food groups ${ }^{(19-22)}$ or the variety of terms used to refer to added sugars on food labels ${ }^{(19,21)}$. Brazilian data on these topics are not available. In the light of the above, the present study aimed to investigate the presence and types of added sugars in the ingredients lists of packaged food products sold in Brazil.

\section{Methods}

\section{Study design}

The present cross-sectional study investigated all retail packaged food products available in a large Brazilian supermarket. The supermarket was chosen purposely and belongs to one of the ten largest Brazilian chain stores, according to the Brazilian Supermarket Association, with twenty-seven stores throughout the country ${ }^{(23)}$. Most of the products sold in this supermarket are of well-known food and beverage brands and represent products sold in other large supermarket chain stores throughout the country. This same study design and data gathering method have been used in previous studies ${ }^{(24-27)}$.

A survey was performed by mapping all aisles in the supermarket; data collectors were responsible for mapping every product in assigned aisles. All packaged food products available in the supermarket that met criteria established by the Brazilian and Mercosur regulation on food labelling (no. 360/2003) were included in the audit $^{(28)}$

\section{Data collection}

Data were gathered over a 3-month period (October to December 2013) in the city of Florianópolis, Santa Catarina, southern Brazil. Information on product name and type, nutritional values (energy, carbohydrates, protein, total fat, saturated fat, trans fat, fibre and sodium contents per serving) and serving sizes were obtained in-store from labels of all available products. These data were then fed into an electronic version of the data collection form developed by Kliemann et al. ${ }^{(29)}$. The electronic form was created using Epi Collect Plus software and was installed on tablet computers. All food labels were photographed in-store to record the ingredients lists, which were later transcribed to the electronic form outside the supermarket.
This procedure was adopted so as not to disturb shoppers, as transcribing requires a long time to be executed.

To improve quality control of data, as in a previous study $^{(25)}$, the inter-rater agreement between the photographs and data transcribed to the electronic forms was evaluated for $5 \%$ of the products. Kappa test results showed a high degree of inter-rater agreement between the two databases $(>99 \% ; P<0 \cdot 05)$.

All data collectors $(n 12)$ received training and participated, one month before data collection, in a field test in a different supermarket.

\section{Data management}

Collected data were transferred directly from the tablet computers to an online database at the end of each collection day. The database was exported to a Microsoft Excel $^{\circledR} 2010$ spreadsheet. Each food product was coded with a number and, later, each image in the database was renamed to the corresponding food product number.

\section{Identification of added sugars in packaged foods}

All ingredients listed on the label of each product were transcribed from the photographic records to the Microsoft Excel $^{\circledR} 2010$ spreadsheet. For quality control purposes, transcribed data were checked by three researchers.

For the identification of added sugars in packaged foods, it was first necessary to identify the terms that refer to these components in the ingredients list. For this, all ingredients that appeared in the database were listed and those that referred to added sugars were identified with the aid of scientific literature and food regulations.

Packaged foods were classified into eight food groups according to similarities in nutritional composition, as defined by a Brazilian and Mercosur resolution ${ }^{(30)}$. To identify the frequency of foods that contained added sugars in each food group, a cluster analysis was performed using a text mining technique in $\mathrm{R}$ statistical environment.

Data were organised and analysed using descriptive statistics, with absolute and relative frequencies of added sugars according to food group, to investigate the use of added sugars in packaged foods sold in Brazil. The $\chi^{2}$ test $(P<0.05)$ was used to compare the presence of added sugars among the groups defined by legislation. The statistical software package Stata version 11.0 was employed.

\section{Results}

Ingredients lists of 4539 packaged foods available for sale during the data collection period were analysed, of which $70 \cdot 8 \%$ ( $n$ 3214) had at least one type of added sugar. Characteristics and distribution of products with added sugars according to food group are shown in Table 1. 
Table 1 Characterisation of packaged foods and the presence of added sugars, according to food group, on the ingredients lists of 4539 packaged food products available in a large supermarket in Florianópolis, Santa Catarina, Brazil, October-December 2013

\begin{tabular}{|c|c|c|c|c|}
\hline Food group & $\begin{array}{c}\text { No. of } \\
\text { products }\end{array}$ & $\begin{array}{l}\text { No. of products } \\
\text { containing } \\
\text { added sugars }\end{array}$ & $\begin{array}{l}\% \text { of products } \\
\text { containing } \\
\text { added sugars* }\end{array}$ & $\begin{array}{l}\text { Examples of foods containing } \\
\text { added sugars }\end{array}$ \\
\hline $\begin{array}{l}\text { Products in which carbohydrates and fats are the } \\
\text { main energy sources }\end{array}$ & 1717 & 1589 & 93 & $\begin{array}{l}\text { Cakes with filling and frosting, } \\
\text { jam, cookies }\end{array}$ \\
\hline Fruits, juices, syrups, and drink mix & 229 & 201 & 88 & $\begin{array}{l}\text { Juice, nectars and fruit drinks, } \\
\text { coconut water }\end{array}$ \\
\hline Milk and dairy products & 359 & 228 & 64 & $\begin{array}{l}\text { Dairy drinks, fermented milk and } \\
\text { yoghurt, creamy cheese }\end{array}$ \\
\hline Meats and eggs & 484 & 293 & 61 & Sausage, hamburger, ham \\
\hline $\begin{array}{l}\text { Gravies, sauces, ready-made seasonings, broths, } \\
\text { soups and ready-to-eat dishes }\end{array}$ & 308 & 188 & 61 & $\begin{array}{l}\text { Soup mix, lasagne, seasoning } \\
\text { cubes }\end{array}$ \\
\hline Canned vegetables & 221 & 128 & 58 & Tomato sauce, pickled vegetables \\
\hline $\begin{array}{l}\text { Bakery goods, bread, cereals, legumes, roots, tubers } \\
\text { and related products }\end{array}$ & 941 & 481 & 51 & Granola bars, bread, cake mix \\
\hline Oils, fats and nuts & 280 & 106 & 38 & Bacon, mayonnaise, nuts mix \\
\hline TOTAL & 4539 & 3214 & 708 & 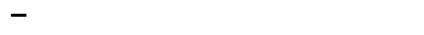 \\
\hline
\end{tabular}

${ }^{*}$ There was a significant difference between the frequencies of each group $(P<0.01)$ according to the $x^{2}$ test of heterogeneity.

A significant difference was observed between groups regarding the frequency of foods with added sugars $(P<0 \cdot 01)$. The group 'products in which carbohydrates and fats are the main energy sources' had a frequency of added sugars 2.4 times (145\%) higher than the group 'oils, fats and nuts', which had the lowest frequency.

In seven of the eight food groups, added sugars were present in more than $50 \%$ of the products. Even in the group with the lowest frequency of added sugars ('oils, fats and nuts'), $38 \%$ of the products had at least one type of these components.

In total, 179 different terms for added sugars were identified in the packaged foods. When analysing the terms, variations in types of sweet spreads and juices were included (e.g. 'apple juice' was identified as a term and 'grape juice' as another term) ${ }^{(3)}$ and variations in terms referring to ingredients' quality and/or purity were not considered (e.g. 'organic' in 'organic sugar'; Table 2).

These terms appeared 7093 times in the 3214 food products containing added sugars, representing an average of 2.2 types of added sugars per product. The most common types of added sugars in ingredients lists were sugar, maltodextrin and glucose syrup.

\section{Discussion}

To the authors' best knowledge, the present study is the first one that systematically analysed the presence and types of added sugars in packaged foods available for sale in South America. In our study, more than $70 \%$ of the analysed foods had at least one type of added sugar in their composition. Such proportion was similar to those identified in studies in the USA $(68.0 \%)^{(21,22)}$, Canada $(63.5 \%)^{(19)}$ and China $(72 \cdot 0$ $\%)^{(20)}$, indicating that added sugars are largely used in packaged foods throughout the world.

In total, 179 different terms for added sugars were identified in the present study. It should be noted that consumers may have trouble in identifying some denominations, such as maltodextrin, dextrose, corn glucose and fructose. In Canada ${ }^{(19)}, 152$ different types of free sugars were identified in packaged foods marketed in supermarkets under names that might be difficult to understand by the population.

In the scientific literature, there are few studies that evaluate the understanding of terms referring to added sugars and/or free sugars by consumers. In a study with 445 adults in the UK, only $4 \%$ of participants correctly classified ten or more ingredients from a list of thirteen items as added sugars or artificial sweeteners. Half of the participants failed to classify terms difficult to understand, such as isoglucose or invert sugar ${ }^{(31)}$.

Contrary to what has been observed in studies in the USA, where corn syrup is the main type of added sugar in processed foods $^{(21,22)}$, the present study identified refined sugar as the most frequent ingredient, accounting for $40 \%$ of the total number observed. Brazil is the world's largest sugar producer and the third largest consumer ${ }^{(32)}$, which may explain the extensive use of this ingredient in the evaluated packaged foods sold in the Brazilian supermarket.

Maltodextrin was the second most prevalent added sugar $(8.3 \%)$ in the analysed Brazilian products. Chemically, maltodextrin is classified as an oligosaccharide ${ }^{(33)}$. Its use in packaged foods is indicated as a substitute for sugars and fats, acting mainly as a bulking agent ${ }^{(34)}$.

The analysis per food group showed that the group 'products in which carbohydrates and fats are the main energy sources' had the highest frequency of products with added sugars. As expected, almost all products in this group (93\%), which includes sweet biscuits, cakes, jams, and chocolate, had added sugars. Noteworthy, this group also had the largest number of packaged foods available for sale, $38 \%$ of the total number of products, characterising the high availability of foods with added sugars for the population. 
Table 2 Terms for added sugars, classified into major groups, identified from the ingredients lists of 4539 packaged food products available in a large supermarket in Florianópolis, Santa Catarina, Brazil, October-December 2013

\begin{tabular}{|c|c|}
\hline Type of added sugar & Examples of terms* \\
\hline Sugars & $\begin{array}{l}\text { Sugar, vanilla sugar, } \\
\text { caramelised sugar, crystal } \\
\text { sugar, invert crystal sugar, } \\
\text { demerara sugar, invert sugar, } \\
\text { liquid sugar, invert liquid } \\
\text { sugar, brown sugar, invert } \\
\text { brown sugar, refined sugar, } \\
\text { sucrose, dextrose, corn } \\
\text { dextrose, glucose, corn } \\
\text { glucose, glucose powder, } \\
\text { fructose, lactose }\end{array}$ \\
\hline Maltodextrin & $\begin{array}{l}\text { Maltodextrin, corn starch } \\
\text { maltodextrin, potato } \\
\text { maltodextrin, corn maltodextrin }\end{array}$ \\
\hline Honey and cane syrup & $\begin{array}{l}\text { Honey, royal jelly, molasses, } \\
\text { cane syrup }\end{array}$ \\
\hline Syrups & $\begin{array}{l}\text { Sugar syrup, high-fructose } \\
\text { syrup, caramel syrup, glucose } \\
\text { syrup, glucose-fructose } \\
\text { syrup, guarana syrup, corn } \\
\text { syrup, corn syrup with high- } \\
\text { fructose content, high-fructose } \\
\text { corn syrup, glucose syrup } \\
\text { solids }\end{array}$ \\
\hline Sweet spreads and jams $†$ & $\begin{array}{l}\text { Sweet spreads and jams made } \\
\text { of fruits and/or vegetables }\end{array}$ \\
\hline $\begin{array}{l}\text { Fruit or vegetable juices, pulps, } \\
\text { preserves, sauces and dried } \\
\text { fruits } \dagger\end{array}$ & $\begin{array}{l}\text { Fruit and/or vegetable juices, } \\
\text { fruit and/or vegetable juice } \\
\text { concentrates, whole fruit } \\
\text { juices, fruit and/or vegetable } \\
\text { pulps, mashed fruits and/or } \\
\text { vegetables, fruit sauces, dried } \\
\text { and/or dehydrated fruits }\end{array}$ \\
\hline Others & $\begin{array}{l}\text { Sweetened condensed milk, } \\
\text { marshmallow }\end{array}$ \\
\hline
\end{tabular}

*In total, 179 different terms for added sugars were identified, excluding quality and/or purity variations (e.g. 'organic sugar' or ' $100 \%$ fruit juice from concentrate').

†Different fruit flavours not specified here were included (e.g. 'orange juice', 'watermelon juice', etc.). Therefore, there are fewer examples in the table than the total number of terms identified.

In addition, there was a high frequency of packaged foods with added sugars in groups of predominantly salty foods: 'gravies, sauces, ready-made seasonings, broths, soups and ready-to-eat dishes' (61\%); 'meats and eggs' (60\%); and 'canned vegetables' (58\%). In these products, sugars may have been used as a preservative, acid stabiliser, colorant or flavour enhancer ${ }^{(34,35)}$. The use of sugars in salty products may lead consumers to eat added sugars without knowing. As these products do not have a characteristic sweet taste, the presence of sugar probably would not be expected or perceived.

In Brazil, as well as in other countries where the declaration of sugar content is not mandatory, the ingredients list remains the only means of estimating the presence, but not the quantity, of added sugars in packaged foods. However, according to the present study results, the diversity of terms used for added sugars may hamper their identification and consequently the adoption of the WHO recommendation to limit sugar consumption.
These issues could be minimised with a quantitative statement of added sugars on the nutrition information label of packaged foods, which is especially important because the WHO provides quantitative recommendations for the intake of added sugars ${ }^{(7)}$. In the USA and Canada, declaration of added sugars on packaged food labels in grams and percentage of daily value (\%DV) is mandatory $^{(2,18)}$. In Canada, a footnote must be included in nutrition labels to indicate whether the food has 'a lot' or 'a little' of sugar according to the \%DV and ingredients defined as added sugars are grouped into a single category in the ingredients list under the term 'sugars'(18). Such information may assist consumers in identifying the presence and types of added sugars in packaged foods.

Considering the results of the present study, we suggest that Brazilian legislation on nutrition labelling should be revised. Specifically, quantitative declaration of added sugars in packaged foods must be mandatory, as already occurs in other countries. We also suggest that regulations concerning the presentation of added sugars in the ingredients list should be modified to ensure that (i) the terms used to refer to added sugars are standardised and (ii) added sugars are grouped in the ingredients list, as proposed and implemented in Canada ${ }^{(18)}$.

Regarding our recommendation for a quantitative declaration of added sugars on food labels, we acknowledge the challenge of quantifying sugars according to their origin, either naturally occurring or added, as no analytical methods are currently available for this measurement ${ }^{(36)}$. However, manufacturers know the amounts of sugar-based ingredients added to their products $^{(37)}$ and could easily state this information on nutrition information labels. Such initiative could promote a reduction in the consumption of added sugars by consumers and perhaps encourage manufacturers to modify product formulations.

Studies have shown that reformulation of products by manufacturers may involve the use of low-calorie sweeteners as substitutes for added sugars ${ }^{(1,33,37)}$. However, frequent consumption of low-calorie sweeteners has been associated with adverse health effects ${ }^{(38-41)}$. Therefore, from a health perspective, the substitution of sugars with low-calorie sweeteners may not be advantageous. For this reason, the Pan-American Health Organization's Nutrient Profile Model declares that the use of low-calorie sweeteners should be limited to promote the development of products with better nutritional profiles ${ }^{(42)}$.

To summarise, the present study contributes to the literature by showing the magnitude of the presence of added sugars in packaged foods commercialised in Brazil. We highlight the major importance of food labelling in allowing consumers to make informed food choices and the lack of studies on added sugars in Brazil. As future directions, we believe that data gathered during our study can be used for monitoring the nutritional quality of packaged foods marketed in the country. 


\section{Study limitations and strengths}

As limitations of the present study, we highlight the difficulty in classifying certain packaged foods not covered by Regulation No. 359/2003, such as hydroponic and lyophilised vegetables, which were not common in Brazil when this regulation was implemented ${ }^{(30)}$. In addition, the limitations that arise from gathering data from only one supermarket must be considered. As the study was conducted in a large supermarket in southern Brazil, data may not reflect the profiles of products sold throughout the country. As frequently occurs, our data may underestimate the frequency of foods containing added sugars in lowincome regions of the country, as markets in low-income areas tend to offer foods with worse nutritional profiles. Nevertheless, we state that care was taken during the selection of the supermarket to ensure that our database consisted of products of well-known brands that are found in other parts of the country.

To the best of our knowledge, our survey is the fifth in Brazil investigating all food product labels in a single supermarket; the other studies were conducted in the same supermarket chain as that of the present study ${ }^{(24-27,43-49)}$.

\section{Conclusion}

Most of the analysed packaged foods (71\%) had added sugars in their composition, of which refined sugar was the most prevalent ingredient. Although added sugars were more frequent in sweet foods, they were also observed with a high frequency in salty foods, which could lead consumers to increase added sugars consumption without knowing.

There were 179 different terms for added sugars in ingredients lists, which may hamper their identification on food labels by consumers. For this reason, the amount of added sugars should be stated on nutrition information labels. Moreover, we recommend that laws should be established to standardise the classification of ingredients that contain added sugars and to group sugar-based ingredients under a category with the generic name of 'sugar' to facilitate identification. In addition, the promotion of knowledge on terms that refer to added sugars by organisations such as councils and associations of health professionals could be a strategy to assist consumers in identifying these sugars in packaged foods.

Thus, considering the recommendations of limiting the intake of added sugars by government agencies, data on the presence and types of these sugars in packaged foods should be available to researchers, health professionals and consumers. These results may also serve as a basis for future comparisons of trends in the use and types of added sugars in packaged foods.

\section{Acknowledgements}

Financial support: The authors thank the Federal Agency for Support and Evaluation of Graduate Education in Brazil (CAPES) for its financial support in the form of scholarships to T.S. This analysis was conducted as part of a wider study about the comprehension and use of food labelling in Brazil, which was funded by the National Council for Scientific and Technological Development (CNPq) of the Ministry of Science and Technology in Brazil and by the Brazilian Health Surveillance Agency (ANVISA) (grant number 440040/2014-0), with the aim of filling gaps related to the policies, management and organisation of the Brazilian National Health Surveillance System. The funders had no role in the design, analysis or writing of this article. Conflicts of interest: None. Authorship: T.S. was responsible for planning the research, collecting, analysing and interpreting data, and drafting the manuscript. A.C.F. was responsible for collecting, analysing and interpreting data, and revising the manuscript. A.A. was responsible for statistical analyses and for revising the manuscript. R.P.C.P. was responsible for the design of the original study, planning the research and analysis, research coordination, and supervising and revising the final manuscript. All authors approved the version submitted for publication. Etbics of human subject participation: Not applicable.

\section{References}

1. US Department of Agriculture \& US Department of Health and Human Services (2015) 2015-2020 Dietary Guidelines for Americans, 8th ed. Washington, DC: US Government Printing Office; available at http://health.gov/dietaryguidelines/ 2015/guidelines

2. US Food and Drug Administration, US Department of Health and Human Services (2016) Food Labeling: Revision of the Nutrition and Supplement Facts Labels. Washington, DC: FDA.

3. Scapin T, Fernandes AC \& Proença RPC (2017) Added sugars: definitions, classifications, metabolism and health implications. Rev Nutr 30, 663-667.

4. Moynihan PJ \& Kelly SAM (2014) Effect on caries of restricting sugars intake: systematic review to inform WHO guidelines. J Dent Res 93, 8-18.

5. Te Morenga L, Mallard S \& Mann J (2013) Dietary sugars and body weight: systematic review and meta-analyses of randomised controlled trials and cohort studies. BMJ $\mathbf{3 4 6}$, e7492.

6. Te Morenga LA, Howatson AJ, Jones RM et al. (2014) Dietary sugars and cardiometabolic risk: systematic review and meta-analyses of randomized controlled trials of the effects on blood pressure and lipids. Am J Clin Nutr 100, 65-79.

7. World Health Organization (2015) Guideline: Sugars Intake for Adults and Children. Geneva: WHO.

8. Powell ES, Smith-Taillie LP \& Popkin BM (2016) Added sugars intake across the distribution of US children and adult consumers: 1977-2012. J Acad Nutr Diet 116, $1543-1550$. 
9. Steele EM, Baraldi LG, Louzada MLC et al. (2016) Ultraprocessed foods and added sugars in the US diet: evidence from a nationally representative cross-sectional study. $B M J$ Open 6, e009892.

10. Moubarac JC, Batal M, Louzada MLC et al. (2017) Consumption of ultra-processed foods predicts diet quality in Canada. Appetite 108, 512-520

11. Bates B, Lennox A, Prentice A et al. (2014) National Diet and Nutrition Survey Results from Years 1, 2, 3 and 4 (combined) of the Rolling Programme (2008/2009-2011) 2012). London: Public Health England.

12. Lei L, Rangan A, Flood VM et al. (2016) Dietary intake and food sources of added sugar in the Australian population. $\mathrm{Br}$ J Nutr 115, 868-877.

13. Pereira RA, Duffey KJ, Sichieri R et al. (2014) Sources of excessive saturated fat, trans fat and sugar consumption in Brazil: an analysis of the first Brazilian nationwide individual dietary survey. Public Health Nutr 17, 113-121.

14. World Health Organization \& Food and Agriculture Organization of the United Nations (2007) Codex Alimentarius: Food Labelling. Rome: Codex Alimentarius Commission.

15. Salud Ministerio de, Pública Subsecretaría de Salud (2016) Ley 20606 - Sobre composición nutricional de los alimentos y su publicidad. Santiago: Ministerio de Salud.

16. Food Standards Australia New Zealand (2018) Nutrition information panels. http://www.foodstandards.gov.au/ consumer/labelling/panels/Pages/default.aspx (accessed in June 2018).

17. European Commission (2011) Regulation (EU) No. 1169/ 2011 of the European Parliament and of the Council of 25 October 2011 on the provision of food information to consumers. Official Journal of the European Union 22.11.2012, L304/18-L304/68.

18. Government of Canada (2016) Regulations Amending the Food and Drug Regulations (Nutrition Labelling, Other Labelling Provisions and Food Colours). Canada Gazette Part 2, 150, issue 25.

19. Bernstein JT, Schermel A, Mills CM et al. (2016) Total and free sugar content of Canadian prepackaged foods and beverages. Nutrients $\mathbf{8}$, E582.

20. Lv J, Chen Y, Wang S et al. (2011) A survey of nutrition labels and fats, sugars, and sodium ingredients in commercial packaged foods in Hangzhou, China. Public Health Rep 126, 116-122.

21. Ng SW, Bricker G, Li KP et al. (2015) Estimating added sugars in US consumer packaged goods: an application to beverages in 2007-08. J Food Compost Anal 43, 7-17.

22. Ng SW, Slining MM \& Popkin BM (2012) Use of caloric and noncaloric sweeteners in US consumer packaged foods, 2005-2009. J Acad Nutr Diet 112, 1828-1834.

23. Brazilian Supermarket Association (2013) Abras Ranking 2013. Revista SUPERHiPER. Brasília, DF: ABRAS; available at http://www.asbra.com.br/noticia/ranking-abras-2013-conhecaas-20-maiores-redes-supermercadistas-do-pais

24. Martins CA, de Sousa AA, Veiros MB et al. (2015) Sodium content and labelling of processed and ultra-processed food products marketed in Brazil. Public Health Nutr 18, 1206-1214

25. Rodrigues VM, Rayner M, Fernandes AC et al. (2016) Comparison of the nutritional content of products, with and without nutrient claims, targeted at children in Brazil. $\mathrm{Br} J$ Nutr 115, 2047-2056.

26. Silveira BM, Gonzalez-Chica DA \& da Costa Proenca RP (2013) Reporting of trans-fat on labels of Brazilian food products. Public Health Nutr 16, 2146-2153.

27. Figueiredo LS, Scapin T, Fernandes AC et al. (2018) Where are the low-calorie sweeteners? An analysis of the presence and types of low-calorie sweeteners in packaged foods sold in Brazil from food labelling. Public Health Nutr 21, $447-453$
28. Ministry of Health, Brazilian Health Surveillance Agency (2003) Resolution-RDC n. 360, of December 23, 2003 (Approves the Technical Rules for Packaged Food Labelling, and Become it Mandatory). Brasília, DF: ANVISA.

29. Kliemann N, Veiros MB, González-Chica DA et al. (2014) Reference serving sizes for the Brazilian population: an analysis of processed food labels. Rev Nutr 27, 329-341.

30. Ministry of Health, Brazilian Health Surveillance Agency (2003) Resolution-RDC n. 359, of December 23, 2003 (Approves the Technical Rules for Packaged Food Serving Sizes for Purposes of Food Labelling). Brasilia, DF: ANVISA.

31. Tierney M, Gallagher AM, Giotis ES et al. (2017) An online survey on consumer knowledge and understanding of added sugars. Nutrients $\mathbf{9}, 37$.

32. US Department of Agriculture \& US Department of Health and Human Services (2013) Sugar and Sweeteners: Outlook. Washington, DC: US Government Printing Office.

33. World Health Organization \& Food and Agriculture Organization of the United Nations (1998) Carbohydrates in Human Nutrition. Report of a Joint FAO/WHO Expert Consultation. FAO Food and Nutrition Paper no. 66. Rome: FAO.

34. Goldfein KR \& Slavin JL (2015) Why sugar is added to food: food science 101. Compr Rev Food Sci Food Saf 14, 644-656

35. Clemens RA, Jones JM, Kern M et al. (2016) Functionality of sugars in foods and health. Compr Rev Food Sci Food Saf 15, 433-470.

36. Louie JC, Moshtaghian H, Boylan S et al. (2015) A systematic methodology to estimate added sugar content of foods. Eur J Clin Nutr 69, 154-161.

37. Pomeranz JL (2012) The bittersweet truth about sugar labeling regulations: they are achievable and overdue. $\mathrm{AmJ}$ Public Health 102, 14-20.

38. Qurrat-ul-Ain \& Khan SA (2015) Artificial sweeteners: safe or unsafe? J Pak Med Assoc 65, 225-227.

39. Rogers PJ, Hogenkamp PS, de Graaf C et al. (2016) Does low-energy sweetener consumption affect energy intake and body weight? A systematic review, including metaanalyses, of the evidence from human and animal studies. Int J Obes (Lond) 40, 381-394.

40. Greenwood DC, Threapleton DE, Evans CE et al. (2014) Association between sugar-sweetened and artificially sweetened soft drinks and type 2 diabetes: systematic review and dose-response meta-analysis of prospective studies. Br J Nutr 112, 725-734.

41. Swithers SE (2013) Artificial sweeteners produce the counterintuitive effect of inducing metabolic derangements. Trends Endocrinol Metab 24, 431-441.

42. World Health Organization \& Pan American Health Organization (2016) Pan American Health Organization Nutrient Profile Model. Washington, DC: PAHO.

43. Kliemann N, Veiros MB, González-Chica DA et al. (2014) Is the serving size and household measure information on labels clear and standardized? Analysis of the labels of processed foods sold in Brazil. Vigil Sanit Debate 2, $62-68$.

44. Kliemann N, Veiros MB, González-Chica DA et al. (2016) Serving size on nutrition labeling for processed foods sold in Brazil: relationship to energy value. Rev Nutr 29, 741-750.

45. Kraemer MV, Oliveira RC, Gonzalez-Chica DA et al. (2016) Sodium content on processed foods for snacks. Public Health Nutr 19, 967-975.

46. Kraemer MVS, Machado PP, Kliemann N et al. (2015) The Brazilian population consumes larger serving sizes than those informed on labels. Br Food J 117, 719-730.

47. Machado PP, Kraemer MVS, Kliemann N et al. (2016) Serving sizes and energy values on the nutrition labels of regular and diet/light processed and ultra-processed dairy products sold in Brazil. Br Food J 118, 1579-1593. 
48. Nishida W, Fernandes AC, Veiros MB et al. (2016) A comparison of sodium contents on nutrition information labels of foods with and without nutrition claims marketed in Brazil. Br Food J 118, 1594-1609.
49. Silveira BM, Kliemann N, Silva DP et al. (2013) Availability and price of food products with and without trans fatty acids in food stores around elementary schools in low- and medium-income neighborhoods. Ecol Food Nutr 52, 63-75. 